\title{
Effects of Neonatal Corticosteroid Treatment on Hippocampal Synaptic Function
}

\author{
CHIUNG-CHUN HUANG, HSIUE-RU LIN, YING-CHING LIANG, AND KUEI-SEN HSU \\ Department of Pharmacology, College of Medicine, National Cheng Kung University, Tainan City 701, Taiwan
}

\begin{abstract}
There is growing concern about long-term neurodevelopmental outcomes after neonatal corticosteroid treatment for chronic lung disease (CLD). Here, we use a protocol with tapering doses of dexamethasone (DEX) or hydrocortisone (HC) proportional to those used in preterm infants to examine the long-term consequences of these treatments on hippocampal synaptic plasticity and associative memory in later life. We found that neonatal DEX, but not $\mathrm{HC}$, treatment impairs long-term potentiation (LTP) but enhances long-term depression (LTD) induction in adolescent rats. The effects of neonatal DEX treatment on LTP and LTD were prevented when the animals were given glucocorticoid receptor antagonist, RU38486, before DEX administration. We also found that neonatal DEX, but not $\mathrm{HC}$, treatment induces a profound increase in the autophosphorylation of $\alpha$ isoform of $\mathrm{Ca}^{2+} /$ calmodulin-dependent protein kinase II at threonine-286 and a decrease in the protein phosphatase 1 expression. In addition, only neonatal DEX treatment disrupts memory retention in rats subjected to passive avoidance learning tasks. These results demonstrate that only neonatal DEX treatment alters the hippocampal synaptic plasticity and associative memory formation in later life and thus suggest that HC may be a safer alternative to DEX for the treatment of CLD in the neonatal period. (Pediatr Res 62: 267-270, 2007)
\end{abstract}

$\mathrm{C}$ orticosteroids, in particular DEX, have been widely used to prevent or treat CLD in preterm infants (1-3). However, there is growing clinical and experimental evidence that this therapy may adversely affect somatic growth and neurodevelopmental outcomes (4-8). Three recent retrospective studies have shown that postnatal HC treatment for CLD had less prominent or even absence of adverse effects on neurodevelopment compared with DEX therapy at school age (e.g. a reduction of cortical gray matter volume) (9-11). In addition, it has also been shown that HC-treated infants had significantly better school performance in comparison with their DEX-treated counterparts at 5-7 y of age (9). Therefore, it was deemed of interest to compare in detail the long-term effects of DEX and $\mathrm{HC}$ treatment on brain function during early development. Because controlled prospective and mechanistic studies in human material are limited, a plausible way to address these questions is using an experimental animal model that closely reproduces a clinical setting for corticosteroid treatment in preterm human neonates. In the present

Received January 11, 2007; accepted March 30, 2007.

Correspondence: Kuei-Sen Hsu, Ph.D., Department of Pharmacology, College of Medicine, National Cheng Kung University, No. 1, University Rd., Tainan City 701, Taiwan; e-mail: richard@mail.ncku.edu.tw

This work was supported by a research grant (NSC95-2752-B-006-002-PAE) from the National Science Council of Taiwan. study, we used a clinically relevant rodent model to compare long-term effects of neonatal treatment with DEX and HC on hippocampal synaptic plasticity and associative memory in adolescent rats. Our results indicate that neonatal DEX, but not HC, treatment switched the direction of synaptic plasticity, favoring LTD over LTP, in the hippocampal CA1 region, as well as an impaired memory retention subjected to a one-trial passive avoidance learning task and that these alterations are highly correlated with an increase in the autophosphorylation of $\alpha$ isoform of $\mathrm{Ca}^{2+} /$ calmodulin-dependent protein kinase II ( $\alpha$ CaMKII) at threonine-286 and a decrease in the protein phosphatase 1 (PP1) expression.

\section{MATERIALS AND METHODS}

Animals. All procedures were performed in accordance with National Institutes of Health guidelines for animal research and approved by the Institutional Animal Care and Use Committee at National Cheng Kung University. Within $6-8 \mathrm{~h}$ after delivery (d 0 ), pups were removed from their nests and six male pups were placed back with each dam. Pups were weaned at $21 \mathrm{~d}$ of age and remained group housed with littermates until experimentation at $5 \mathrm{wk}$ of age.

Drug treatment. Three treatment groups were assigned for each litter: saline (SAL)-, DEX-, and HC-treated animals. Pups in the DEX and HC groups received a daily i.p. injection of DEX or HC (Sigma Chemical Co., St. Louis, MO) between P1 and P3. DEX was given in tapering doses of 0.5 $\mathrm{mg} / \mathrm{kg}$ on $\mathrm{P} 1,0.3 \mathrm{mg} / \mathrm{kg}$ on $\mathrm{P} 2$, and $0.1 \mathrm{mg} / \mathrm{kg}$ on $\mathrm{P} 3$. $\mathrm{HC}$ was given in tapering doses of $5 \mathrm{mg} / \mathrm{kg}$ on P1, $3 \mathrm{mg} / \mathrm{kg}$ on P2, and $1 \mathrm{mg} / \mathrm{kg}$ on P3. Doses of DEX and $\mathrm{HC}$ were selected based on published studies $(7,8)$. Animals in the vehicle group received equivalent volumes of intraperitoneal injection of sterile SAL.

Hippocampal slice preparations and electrophysiology. Hippocampal slices (400 $\mu \mathrm{m}$ thick) were prepared from 5-wk-old rats using standard procedures (8); the rats were allowed to recover for a minimum of $1 \mathrm{~h}$ and then were transferred to a submersion-type recording chamber continually perfused with $30^{\circ} \mathrm{C}-32^{\circ} \mathrm{C}$ oxygenated artificial cerebrospinal fluid (ACSF) solution (in mM: $\mathrm{NaCl}, 117 ; \mathrm{KCl}, 4.7 ; \mathrm{CaCl}_{2}, 2.5 ; \mathrm{MgCl}_{2}, 1.2 ; \mathrm{NaHCO}_{3}, 25$; $\mathrm{NaH}_{2} \mathrm{PO}_{4}, 1.2$; glucose, 11). Extracellular field potential recordings were carried out with Axoclamp-2B amplifier (Molecular Devices, Union City, CA). The responses were low pass-filtered at $2 \mathrm{kHz}$, digitally sampled at 5-10 $\mathrm{kHz}$, and analyzed using pCLAMP software (Version 8.0; Molecular Devices). Postsynaptic responses were evoked in CA1 stratum radiatum by stimulation of Schaffer collateral/commissural afferents at $0.033 \mathrm{~Hz}$ with a bipolar stimulating electrode. Field excitatory postsynaptic potentials (fEPSPs) were recorded with a glass pipette filled with $1 \mathrm{M} \mathrm{NaCl}(2-3 \mathrm{M} \Omega$ resistance) and the initial slope was measured. The long-term potentiation (LTP) was induced by high-frequency stimulation (HFS) at the test pulse intensity, consisting of two 1-s trains of stimuli separated by an intertrain
Abbreviations: $\alpha$ CaMKII, $\alpha$ isoform of $\mathrm{Ca}^{2+} /$ calmodulin-dependent protein kinase II; CLD, chronic lung disease; DEX, dexamethasone; HC, hydrocortisone; HFS, high-frequency stimulation; LFS, low-frequency stimulation; LTD, long-term depression; LTP, long-term potentiation; PP1, protein phosphatase 1; PSD, postsynaptic density; SAL, saline 
interval of $20 \mathrm{~s}$ at $100 \mathrm{~Hz}$. Long-term depression (LTD) was induced by low-frequency stimulation (LFS) delivered at $1 \mathrm{~Hz}$ for $15 \mathrm{~min}$ (900 pulses).

Passive avoidance training and testing. One-trial passive avoidance learning task was selected as the tool for behavioral assessment to measure associative memory retention performance in rats from each group as described previously (8). Each rat was placed individually in the lighted compartment of an automated passive avoidance system (Ugo Basile, Comerio, Italy) and, after entering the dark compartment, was given a scrambled foot shock $(0.5 \mathrm{~mA}$ for $2 \mathrm{~s})$. The retention test was conducted $24 \mathrm{~h}$ later with the rat again being placed in the lighted compartment and subjected to the same protocol described above in the absence of foot shock. The latency (maximum $300 \mathrm{~s}$ ) to enter the dark compartment was scored.

Preparation of postsynaptic density fractions. Isolation of postsynaptic density (PSD) was performed according to the procedure of Wells and colleagues (12). Briefly, the microdissected CA1 regions were homogenized in ice-cold $\mathrm{Ca}^{2+}, \mathrm{Mg}^{2+}$-free buffer $(50 \mathrm{mM}$ HEPES, $100 \mathrm{mM} \mathrm{NaCl}$, and 3 $\mathrm{mM} \mathrm{KAc}, \mathrm{pH} 7.4)$ with RNase inhibitor $(15 \mathrm{U} / \mathrm{mL})$, and the homogenate was centrifuged at $2000 \times g$ for $1 \mathrm{~min}$. Supernatants were passed through two $100-\mu \mathrm{m}$ nylon mesh filters, followed by a $5-\mu \mathrm{m}$ pore filter. The filtrate was centrifuged at $1000 \times g$ for $10 \mathrm{~min}$ and then gently resuspended in same buffer at a protein concentration of $2 \mathrm{mg} / \mathrm{mL}$.

Western blot. For each experimental group, homogenates from at least three slices were pooled. The microdissected subregions were lysed in ice-cold Tris- $\mathrm{HCl}$ buffer solution $(\mathrm{pH}$ 7.4) containing a cocktail of protein phosphatase and proteinase inhibitors $(50 \mathrm{mM}$ Tris- $\mathrm{HCl}, 100 \mathrm{mM} \mathrm{NaCl}, 15$ $\mathrm{mM}$ sodium pyrophosphate, $50 \mathrm{mM}$ sodium fluoride, $1 \mathrm{mM}$ sodium orthovanadate, $5 \mathrm{mM}$ EGTA, $5 \mathrm{mM}$ EDTA, $1 \mathrm{mM}$ phenylmethylsulfonyl fluoride, $1 \mu \mathrm{M}$ microcystin-LR, $1 \mu \mathrm{M}$ okadaic acid, $0.5 \%$ Triton $\mathrm{X}-100,2$ $\mathrm{mM}$ benzamidine, $60 \mu \mathrm{g} / \mathrm{mL}$ aprotinin, and $60 \mu \mathrm{g} / \mathrm{mL}$ leupeptin) to avoid dephosphorylation and degradation of proteins and ground with a pellet pestle (Kontes Glassware, Vineland, NJ). Samples were sonicated and spun down at $15,000 \times g$ at $4^{\circ} \mathrm{C}$ for $10 \mathrm{~min}$. The supernatant was then assayed for total protein concentration using Bio-Rad Bradford Protein Assay Kit (Hercules, CA). Each sample of tissue homogenate or each PSD fraction was separated in $10 \%$ sodium dodecyl sulfate-polyacrylamide gel electrophoresis gel. After the transfer on nitrocellulose membranes, blots were blocked in buffer solution containing $5 \%$ milk and $0.1 \%$ Tween-20 in phosphate-buffered saline $\left(124 \mathrm{mM} \mathrm{NaCl}, 4 \mathrm{mM} \mathrm{KCl}, 10 \mathrm{mM} \mathrm{Na}_{2} \mathrm{HPO}_{4}\right.$, and $\left.10 \mathrm{mM} \mathrm{KH}_{2} \mathrm{PO}_{4}, \mathrm{pH} 7.2\right)$ for $1 \mathrm{~h}$ and then blotted for $2 \mathrm{~h}$ at room temperature with the monoclonal antibody that recognizes phosphorylated $\alpha$ CaMKII at threonine-286 site (1:2000; Affinity Bioreagents, Golden, CO) or protein phosphatase 1 (PP1; 1:1000; Upstate Biotechnology). It was then probed with horseradish peroxidase-conjugated secondary antibody for $1 \mathrm{~h}$ and developed using the electrochemiluminescent immunoblotting detection system (Amersham Biosciences, Buckinghamshire, UK), according to manufacturer's instructions. The immunoblots using phosphorylation site-specific antibodies were subsequently stripped and reprobed with an antibody that recognizes $\alpha$ CaMKII (1:1000; Affinity Bioreagents). Immunoblots were analyzed by densitometry using Bio-profil BioLight PC software.

Data analysis. All data are expressed as means \pm SEM. We used a two-way repeated-measures analysis of variance (ANOVA) to compare LTP and LTD among groups with treatment as the intersubject variable and the time course (time point after HFS or LFS) as the intrasubject variable. Fisher's protected LSD post hoc test was used for pairwise comparisons after ANOVA. Western blot data were analyzed using an unpaired $t$ test. Because passive avoidance performance on training and retention did not assume a normal distribution, these data were analyzed using one-way repeatedmeasures ANOVA, followed by a nonparametric Mann-Whitney $U$ test. Number of animals used is indicated by n. Probability values of $p<0.05$ were considered statistically significant. All data analyses were performed using SPSS commercially available statistical analysis software (SigmaStat Version 2.0; Chicago, IL).

\section{RESULTS}

Effects of neonatal DEX and $H$ treatment on the induction of LTP and LTD. To determine the effects of neonatal DEX and $\mathrm{HC}$ on long-term synaptic plasticity, we analyzed LTP and LTD in the CA1 region of the hippocampus. In slices from SAL-treated rats, conditioning HFS induced a robust LTP (50 min after HFS: $155 \pm 11 \%, n=6$ ) (Fig. $1 A$ ). There was a striking difference in the effect of DEX or HC treatment on LTP induction. Neonatal DEX, but not HC, treatment impaired LTP induction (DEX, $117.8 \pm 6.3 \%, n=6$; HC, $149.6 \pm 7.8 \%$,
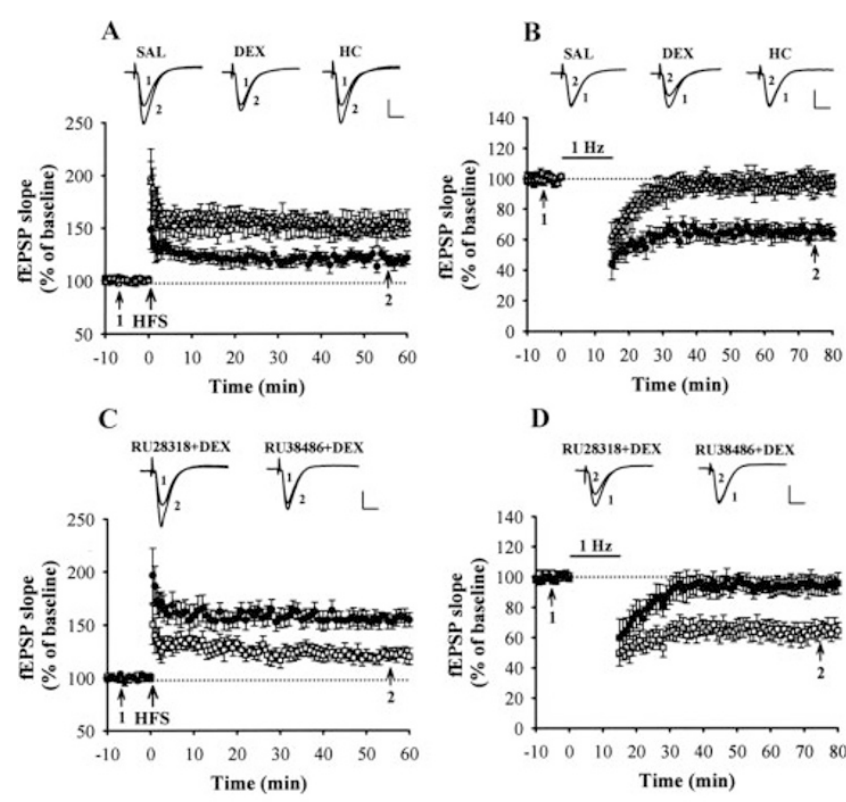

D
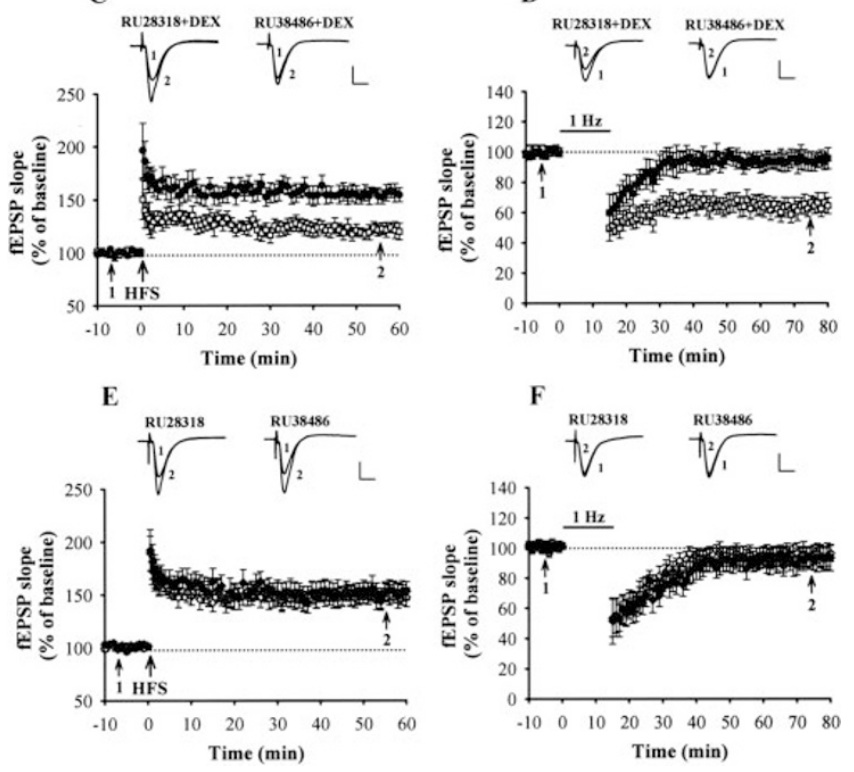

Figure 1. Neonatal DEX, but not HC, treatment impairs LTP induction but facilitates LTD induction in the hippocampal CA1 region. (A) Time course of the slope of the fEPSP before and after HFS (arrow) for hippocampal slices obtained from neonatal SAL- $(\bigcirc)$, DEX- $(\bullet)$, and HC- $(\triangle)$ treated rats. $(B)$ Time course of the slope of the fEPSPs before and after LFS for hippocampal slices obtained from neonatal SAL- $(\bigcirc)$, DEX- $(\bullet)$, and HC- $(\triangle)$ treated rats.

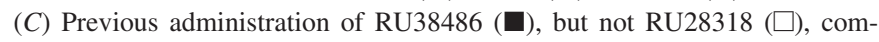
pletely prevented the block of LTP induction by DEX treatment. (D) LFS failed to induce LTD in slices from DEX-treated rats, which administrated RU38486 (ם). Administration of RU28318 did not significantly alter the induction of LTD by LFS in slices from DEX-treated rats $(\square)$. (E) Time course of the slope of the fEPSP before and after HFS for hippocampal slices obtained from neonatal RU28318- $(\diamond)$ or RU38486- $(\diamond)$ treated rats. $(F)$ Time course of the slope of the fEPSP before and after LFS for hippocampal slices obtained from neonatal RU28318- $(\diamond)$ or RU38486- $(\diamond)$ treated rats. The superimposed fEPSPs in the upper portion illustrate respective recordings from example experiments taken at the time indicated by number. Horizontal bar denotes the period of delivery of LFS. Dash lines show level of baseline.

$n=6$ ). During the 60 -min recording time after HFS, a two-way repeated-measures ANOVA of fEPSP slope showed a significant interaction among groups and time course $\left(F_{2,15}=7.158, p<\right.$ $0.01)$. LTD was induced by applying LFS at $1 \mathrm{~Hz}$ for $15 \mathrm{~min}$. As shown in Fig. $1 B$, slices from DEX-treated but not SAL- or HC-treated rats showed a reliable LTD (50 min after the end of LFS: SAL, $96.3 \pm 4.2 \%, n=6$; DEX, $63.6 \pm 5.8 \%, n=6$; HC, $94.7 \pm 4.9 \%, n=6$ ). There was a significant interaction among groups and time course on fEPSP slope $\left(F_{2,15}=39.87, p<\right.$ $0.001)$.

Consistent with a key mechanistic role for glucocorticoid receptor activation in mediating the effects of DEX on hip- 
pocampal plasticity, the specific glucocorticoid receptor antagonist RU38486 (40 mg/kg, i.p. injection $30 \mathrm{~min}$ before DEX), completely prevented the block of LTP $(154.3 \pm 8.5 \%$, $n=6)$ and facilitation of LTD induction (93.5 $\pm 5.8 \%, n=$ 6) by $\mathrm{DEX}$ treatment (Fig. $1 C, D$ ). Conversely, previous administration of the specific mineralocorticoid receptor antagonist RU28318 (10 mg/kg) did not significantly affect the effects of DEX on LTP $(121.2 \pm 6.3 \%, n=4)$ and LTD ( $66.4 \pm 5.7 \%$ of baseline; $n=4)$. However, neither neonatal RU28318 nor RU38486 treatment alone affected the induction of LTP (RU28318, $151.5 \pm 9.3 \%, n=4$; RU38486, $154.5 \pm$ $9.1 \%, n=4 ; p>0.05$ when compared with slices from saline treatment rats) or LTD (RU28318, 96.1 $\pm 5.3 \%, n=4$; RU38486, $94.5 \pm 6.3 \%, n=4 ; p>0.05$ when compared with slices from saline treatment rats) (Fig. $1 E, F$ ).

In previous studies (8), we established that the effects of neonatal DEX treatment on LTP and LTD induction are correlated with an increase in the autophosphorylation of $\alpha \mathrm{CaMKII}$ at threonine-286 in hippocampal PSD fraction and a decrease in the PP1 expression and activity in hippocampal CA1 homogenate. Thus, we also compared the long-term effects of neonatal DEX and HC treatment on the basal levels of phosphorylated $\alpha \mathrm{CaMKII}$ at threonine-286 and PP1 protein expression. As previously shown (8), neonatal DEX treatment led to an increase in the $\alpha$ CaMKII autophosphorylation and a decrease in PP1 when compared with SAL treatment group (Fig. 2A,B). No significant effects of HC treatment on the levels of $\alpha$ CaMKII autophosphorylation and PP1 proteins were seen. Inhibition of glucocorticoid receptor with RU38486 also specifically prevented the effects of DEX on the $\alpha$ CaMKII autophosphorylation and PP1 protein (Fig. 2C, E). In contrast, prior administration of RU28318 did not significantly affect the effects of DEX. Neither neonatal RU28318 nor RU38486 treatment alone caused a significant change in the levels of $\alpha$ CaMKII autophosphorylation or PP1 protein (Fig. 2D, F).

Effects of neonatal DEX and HC treatment on one-trial passive avoidance learning. As a final test, we compared the long-term effects of neonatal DEX and HC treatment on memory retention of one-trial passive avoidance learning task (a form of contextual fear conditioning). No significant between-group differences in performance were noted during the training, but on the day of testing, performance of DEXtreated rats was poorer [i.e. they entered the darkened chamber in which they were previously shocked more rapidly $(23.5 \pm$ $5.2 \mathrm{~s} ; n=8)$ than SAL- $(64.8 \pm 7.5 \mathrm{~s} ; n=8)$ and HC- $(57.6 \pm$ $6.7 \mathrm{~s} ; n=8)$ treated rats] (Fig. 3A). The effect of DEX on memory retention performance was completely prevented by the administration of RU38486 (61.3 $\pm 7.2 \mathrm{~s} ; n=6)$, but not by RU28318 (24.9 $\pm 4.9 \mathrm{~s} ; n=6)$ (Fig. 3B). Neither neonatal RU28318 (67.5 $\pm 7.5 \mathrm{~s} ; n=5)$ nor RU38486 (56.3 $\pm 9.2 \mathrm{~s}$; $n=5$ ) treatment alone significantly affected the memory retention performance (Fig. 3C).

\section{DISCUSSION}

Long-term neurodevelopmental outcomes after neonatal corticosteroid treatment have become a determinant factor
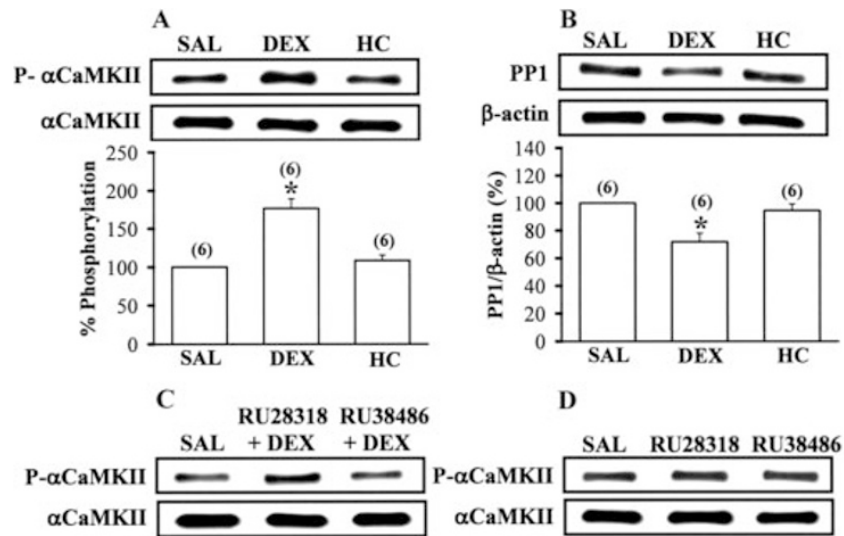

D
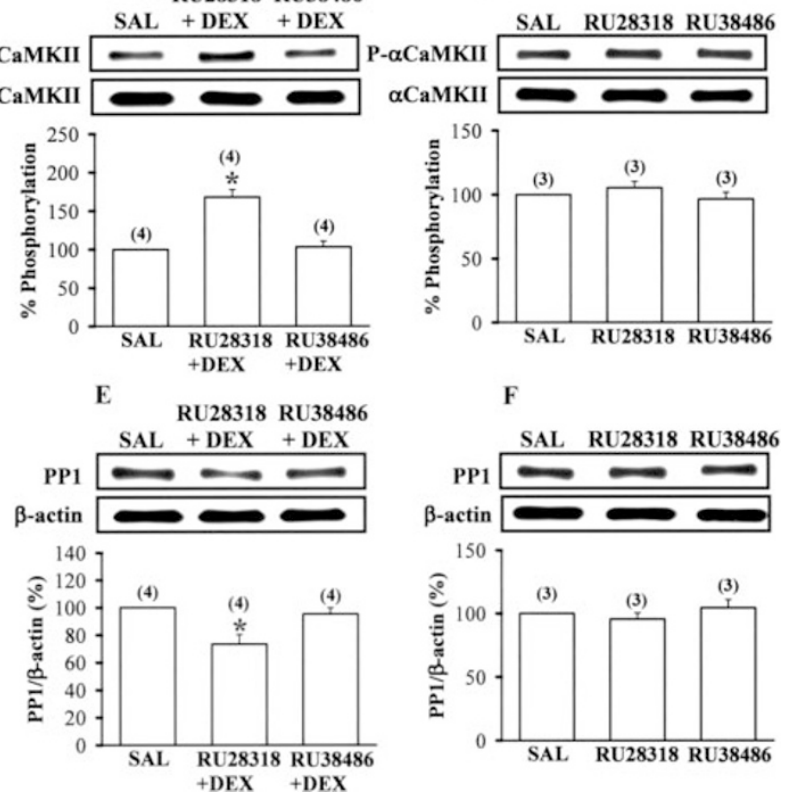

Figure 2. Neonatal DEX, but not HC, treatment leads to an increase in the levels of $\alpha$ CaMKII autophosphorylation but a decrease in PP1 protein expression. (A) Representative blots showing that higher phosphorylation of $\alpha \mathrm{CaMKII}$ at threonine-286 in PSD from DEX-treated rats as compared with SAL- and HC-treated rats. Group data showing the normalization of phosphorylation of $\alpha \mathrm{CaMKII}$ to the nonphosphorylated form was determined in each group. (B) Representative blots showing the levels of PP1 in the hippocampal CA1 homogenates from neonatal SAL-, DEX-, and HC-treated rats. Group data showing the normalization of PP1 to $\beta$-actin was determined in each group. (C) RU38486 pretreatment prevented the up-regulation of $\alpha$ CaMKII autophosphorylation by DEX, while RU28318 had no effect. $(D)$ Representative blots and group data showing the level of $\alpha$ CaMKII autophosphorylation in PSD from neonatal SAL-, RU28318-, and RU38486-treated rats. (E) RU38486 pretreatment specifically blocked the reduction of PP1 protein levels by DEX. $(F)$ Representative blots and group data showing the level of PP1 protein in the hippocampal CA1 homogenates from neonatal SAL-, RU28318-, and RU38486-treated rats. ${ }^{*} p<0.05$, compared with SAL-treated group, unpaired $t$ test.

against the use of this therapy in preterm infants. Although evidence is now increasing that treatment of preterm infants with DEX is associated with an increased risk of impaired neuromotor skills and cognitive function in later life (4-6), it is uncertain whether these abnormalities are linked to the use of corticosteroids in general or just to DEX only. In the present study, besides the confirmation of previous work demonstrating that neonatal DEX treatment alters hippocampal synaptic function in later life $(7,8)$, we show the novel observations that neonatal $\mathrm{HC}$ treatment using a regimen similar to that used in preterm infants has no long-term effects on either hippocampal synaptic plasticity or contextual fear 
A

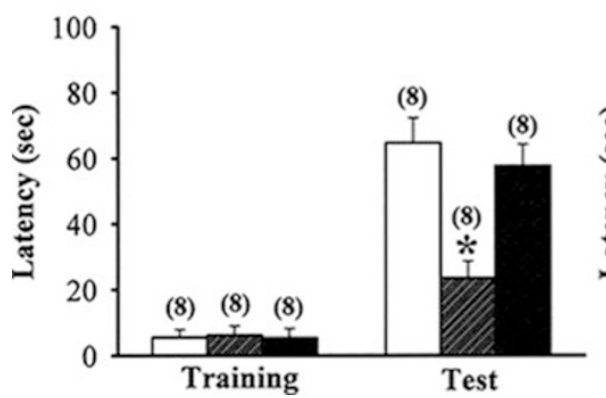

B

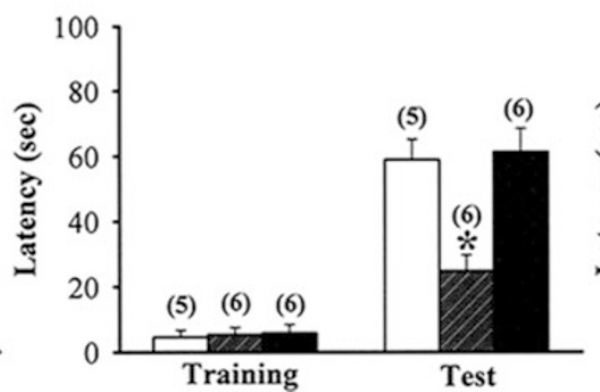

$\mathrm{C}$

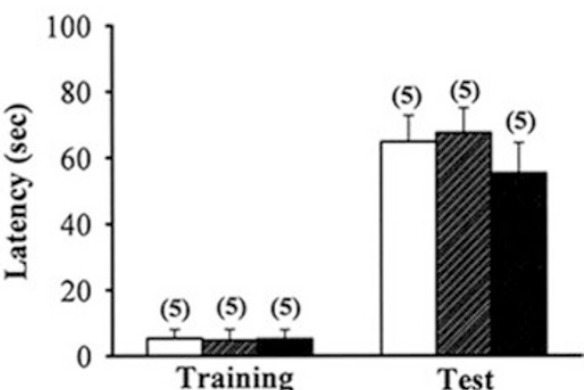

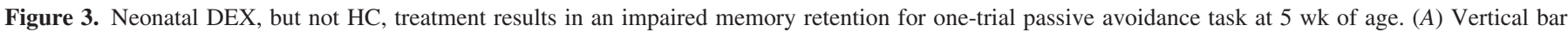

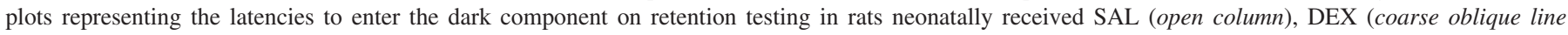

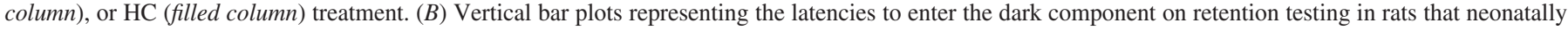

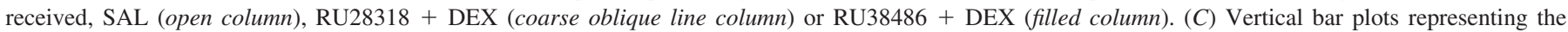

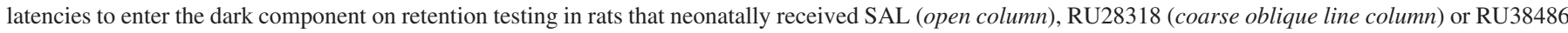
(filled line column). ${ }^{*} p<0.05$, in comparison with SAL-treated group, in a nonparametric Mann-Whitney $U$ test after one-way ANOVA.

memory formation. These findings are in agreement with the neurodevelopmental outcome data of recently published comparison studies of postnatal DEX and HC treatment in preterm infants (9-11) with favorable outcomes for HC treatment.

A key question is why neonatal treatment with $\mathrm{HC}$ can result in quite different neurodevelopmental outcomes compared with DEX. As DEX has a high glucocorticoid-mediated activity (13), low mineralocorticoid-mediated activity and long biologic half-life compared with $\mathrm{HC}$, one potential possibility is that these discrepant outcomes arise from the differential activation of glucocorticoid receptors by these treatments. The present study confirmed the role of glucocorticoid receptor activation in mediating the long-term effects of neonatal DEX treatment by demonstrating that DEX-induced alterations of hippocampal synaptic plasticity and contextual fear memory formation were specifically prevented by the glucocorticoid receptor antagonist RU38486.

In line with previous findings $(7,8)$, we found that, compared with SAL- and HC-treated rats, DEX-treated rats exhibited an increased basal $\alpha$ CaMKII autophosphorylation at threonine-286 in hippocampal PSD fraction. It has been shown that threonine-286 phosphorylation is sufficient to convert the $\alpha$ CaMKII to the high affinity form (14). Thus, it is possible that the greater level of autophosphorylated $\alpha$ CaMKII binds a greater amount of $\mathrm{Ca}^{2+} /$ calmodulin, which in turn leads to systematic shift in favor of LTD at all submaximal levels of $\mathrm{Ca}^{2+}$ influx triggered by LFS. In fact, it has been shown that transgenic mice overexpressing a mutated form of $\alpha$ CaMKII with autonomous activity display a downward shift of the frequency response curve, favoring LTD over LTP induction in the hippocampal CA1 region (15). Because the increase in $\alpha$ CaMKII autophosphorylation observed in DEX-treated rats is correlated with a reduction of PP1 level, it is likely that neonatal DEX treatment may provide a unidentified mechanism for decreased PP1 production, which renders the $\alpha$ CaMKII persistently hyperphosphorylated (8).

In conclusion, our works supports the notion that neonatal HC treatment has no long-term adverse effects on hippocampal function compared with DEX treatment. These findings are of clinical importance because it is now difficult to avoid the use of corticosteroids in neonatology and perinatology to fight the problems of CLD. Although HC may instead of DEX for the prevention or treatment of CLD, further prospective, longitudinal follow-up studies are necessary to evaluate this therapeutic approach.

\section{REFERENCES}

1. Cummings JJ, D’Eugenio DB, Gross SJ 1989 A controlled trial of dexamethasone in preterm infants at high risk for bronchopulmonary dysplasia. N Engl J Med 320: $1505-1510$

2. Lee SK, McMillan DD, Ohlsson A, Pendray M, Synnes A, Whyte R, Chien LY, Sale J 2000 Variations in practice and outcomes in the Canadian NICU network: 1996-1997. Pediatrics 106:1070-1079

3. Lemons JA, Bauer CR, Oh W, Korones SB, Papile LA, Stoll BJ, Verter J, Temprosa M, Wright LL, Ehrenkranz RA, Fanaroff AA, Stark A, Carlo W, Tyson JE, Donovan EF, Shankaran S, Stevenson DK 2001 Very low birth weight outcomes of the National Institute of Child health and human development neonatal research network, January 1995 through December 1996. NICHD Neonatal Research Network. Pediatrics 107:E1

4. Barrington KJ 2001 The adverse neuro-developmental effects of postnatal steroids in the preterm infant: a systematic review of RCTs. BMC Pediatr 1:1

5. Stark AR, Carlo WA, Tyson JE, Papile LA, Wright LL, Shankaran S, Donovan EF, Oh W, Bauer CR, Saha S, Poole WK, Stoll BJ National Institute of Child Health and Human Development Neonatal Research Network 2001 Adverse effects of early dexamethasone in extremely-low-birth-weight infants. National Institute of Child Health and Human Development Neonatal Research Network. N Engl J Med 344:95-101.

6. Yeh TF, Lin YJ, Lin HC, Huang CC, Hsieh WS, Lin CH, Tsai CH 2004 Outcomes at school age after postnatal dexamethasone therapy for lung disease of prematurity. N Engl J Med 350:1304-1313

7. Kamphuis PJ, Gardoni F, Kamal A, Croiset G, Bakker JM, Cattabeni F, Gispen WH, van Bel F, Di Luca M, Wiegant VM 2003 Long-lasting effects of neonatal dexamethasone treatment on spatial learning and hippocampal synaptic plasticity: involvement of the NMDA receptor complex. FASEB J 17:911-913

8. Lin HJ, Huang CC, Hsu KS 2006 Effects of neonatal dexamethasone treatment on hippocampal synaptic function. Ann Neurol 59:939-951

9. van der Heide-Jalving M, Kamphuis PJ, van der Laan MJ, Bakker JM, Wiegant VM, Heijnen CJ, Veen S, van Bel F 2003 Short- and long-term effects of neonatal glucocorticoid therapy: is hydrocortisone an alternative to dexamethasone? Acta Paediatr 92:827-835

10. Lodygensky GA, Rademaker K, Zimine S, Gex-Fabry M, Lieftink AF, Lazeyras F, Groenendaal F, de Vries LS, Huppi PS 2005 Structural and functional brain development after hydrocortisone treatment for neonatal chronic lung disease. Pediatrics 116:1-7

11. Karemaker R, Heijnen CJ, Veen S, Baerts W, Samsom J, Visser GH, Kavelaars A, van Doornen LJ, van Bel F 2006 Differences in behavioral outcome and motor development at school age after neonatal treatment for chronic lung disease with dexamethasone versus hydrocortisone. Pediatr Res 60:745-750

12. Wells DG, Dong X, Quinlan EM, Huang YS, Bear MF, Richter JD, Fallon JR 2001 A role for the cytoplasmic polyadenylation element in NMDA receptor-regulated mRNA translation in neurons. J Neurosci 21:9541-9548

13. De Kloet ER, Vreugdenhil E, Oitzl MS, Joels M 1998 Brain corticosteroid receptor balance in health and disease. Endocr Rev 19:269-301

14. Hanson PI, Meyer T, Stryer L, Schulman H 1994 Dual role of calmodulin in autophosphorylation of multifunctional $\mathrm{CaM}$ kinase may underlie decoding of calcium signals. Neuron 12:943-956

15. Mayford M, Wang J, Kandel ER, O'Dell TJ 1995 CaMKII regulates the frequencyresponse function of hippocampal synapses for the production of both LTD and LTP. Cell 81:891-904 